\title{
Assédio Moral no Trabalho: \\ A Relação com a Cultura Organizacional
}

\author{
Moral Arrest at Work: \\ The Relationship with Organizational Culture
}

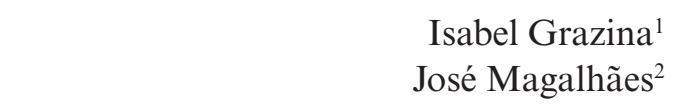

PSIQUE - ISSN 1647-2284 - 2011 - No 7 - pp. 107-130

Recebido em 26-9-2011; aceite em 12-11-2011

Resumo

Nas organizações laborais o fenómeno do assédio moral tem vindo a agravar-se nos últimos anos e tem chamado a atenção de profissionais de diversas áreas em especial da Medicina, Advocacia e da Psicologia. Este trabalho teve como objectivo avaliar em que medida a cultura organizacional pode ser potenciadora do aparecimento do assédio moral no trabalho. Nesse sentido realizou-se um estudo empírico, utilizando uma metodologia quantitativa, com abordagem dedutiva e na análise e interpretação dos dados recolhidos foram utilizados procedimentos estatísticos do PASW Statistics (versão 18). A amostra foi composta por 150 funcionários do ramo bancário e 150 funcionários do ramo da saúde em contexto privado. O instrumento utilizado consistiu na aplicação de um questionário, para medir o nível de incidência do assédio moral no trabalho em termos de auto-percepção dos funcionários, foi utilizado o NAQ-R e para analisar o tipo de cultura organizacional utilizamos o FOCUS-93. Para avaliar a relação existente entre a cultura organizacional e a existência de assédio moral, seguimos duas linhas de orientação, uma fundamentada no modelo dos valores contrastantes de Quinn e outra baseada na teoria do assédio moral de Hirigoyen. Os resultados obtidos demonstraram que a cultura predominante é a de objectivos, que apresenta uma variação explicativa de $90 \%$ do total do aparecimento de assédio moral, por outro lado verificou-se a predominância de assédio vertical descendente, percepcionado pelos colaboradores.

Palavras-chave: Assédio moral; mobbing; Clima organizacional; Cultura organizacional.

1 Mestre em Psicologia Social e Organizacional (isabelgraz@gmail.com) membro da Associação Nacional Contra o Assédio Moral.

2 Docente do DPS da UAL (jmgmaga54@gmail.com). 


\section{Abstract}

In labor organizations the moral arrest has been worsening in the last few years and it called the attention of professionals from several areas such as medicine, law or psychology. The aim of this work was to evaluate how the organizational culture can enhance the moral arrest at work. It has been made an empiric study using a quantitative method with deductive approach and PASW Statistic (version 18) procedures have been used for data analysis and interpretation, being this one a deduction like research. The sample was composed of 150 bank workers and 150 private practice healthcare workers. The instrument used consists on the application of a questionnaire in order to measure the incidence level of moral arrest at work in terms of auto perception. It was used the NAQ-R and to analyze the kind of organizational culture was used FOCUS-93. In order to evaluate the relationship between organizational culture and moral arrest we followed two guidelines, one based on the model of contrasting values of Quinn and the other based on the theory of moral arrest of Hirigoyen. The results we obtained had revealed that the dominant culture is the one of the objectives that has an explanative variation of $90 \%$ of the total of moral arrest. On the other hand it has been verified the dominance of vertical descendent arrest, understood by employees.

Keywords: Moral arrest; Mobbing; Organizational culture; Organizational climate.

\section{Introdução}

Nos últimos anos o assédio moral no trabalho tem sido alvo de reconhecimento a nível mundial como um problema tanto de cariz laboral como social.

O estudo desta temática é de enorme valor, uma vez que o respeito pela dignidade humana deve ter primordial importância a todos os níveis. Note-se que vivemos num contexto socioeconómico em constante mudança, o que origina uma competitividade e flexibilidade organizacional enorme e por conseguinte origina uma disputa constante de poder, que muitas vezes provoca rivalidade. É neste contexto que o assédio prospera.

O conhecimento sobre o assédio moral no local de trabalho tem evoluído significativamente através de diversas investigações, realizadas sobretudo no âmbito da psicologia social e das organizações, no sentido de explicar a ocorrência do fenómeno e aprofundar o conhecimento existente.

Têm vindo a ser promovidas a nível internacional diversas conferências, no sentido de promover e divulgar o conhecimento nesta área, essas conferências têm usufruído de uma enorme adesão tanto no número de países envolvidos como em termos de qualidade e quantidade de comunicações apresentadas. A primeira conferência teve lugar em Stafford (1998), seguindo-se Brisbane (2000), Londres (2002), Bergen (2004), Dublin (2006), Montreal (2008), Cardiff, no País de Gales (Reino Unido), foi a anfitriã da sétima Conferência Internacional sobre o assédio moral no local de trabalho em 
Junho de 2010, estando agendada para Junho de 2012, em Copenhaga na Dinamarca, a oitava Conferência Internacional.

O crescente interesse nesta área específica da saúde no trabalho em termos internacionais, parece estar a criar um contexto que promove a investigação e a intervenção no nosso país, o que se torna evidente pela constatação do crescente número de temas de trabalhos de investigação a nível académico, neste domínio específico, contudo pretendemos também dar um contributo para a investigação nesta área, explorando a cultura organizacional como potenciadora deste fenómeno.

A pertinência do tema, justifica-se pela necessidade de fomentar acções de formação para prevenir o aparecimento desta violência que assola o mundo. Por outro lado, um dos factores de ênfase para a escolha desta temática, foi o facto de termos vivenciado este terror psicológico.

De uma forma global poder-se-á afirmar que o assédio moral no local de trabalho consiste na utilização de comportamentos negativos, hostis e agressivos de carácter persistente e duradouro no tempo, incluindo humilhar, ofender ou excluir socialmente um ou mais indivíduos, afectando negativamente o seu desempenho profissional, criando um ambiente de trabalho hostil. Estes comportamentos típicos de assédio moral não contêm só por si uma conotação negativa e ocorrem por vezes em interacções normais do quotidiano. No entanto, se utilizados frequentemente e repetidamente no decorrer de um período de tempo relativamente longo (superior a seis meses), o seu conteúdo e significado alteram-se, tornando-se em perigosas armas de comunicação (Leymann, 1996).

Devido às graves consequências para a saúde das vítimas deste fenómeno, e para as próprias empresas, tais como: absentismo, quebras de produtividade, ausência de motivação no trabalho, má reputação, entre outros, tem vindo a ser realizada uma crescente investigação a nível europeu, neste domínio. Embora em Portugal as investigações neste campo ainda sejam escassas, é baseado neste contexto que surgem as questões de partida:

i. Será o assédio moral no trabalho percepcionado pelos funcionários?

ii. Será a cultura organizacional potenciadora deste fenómeno?

Alguns factores presentes no dia-a-dia da organização, como por exemplo: diferença hierárquica, diferenças de idade entre os colegas, razões económico-financeiras, diferença étnica, competição interna, stress laboral, prémios e recompensas, reduções de pessoal, ausência de comunicação, entre outros, proporcionam um clima de rivalidade entre os indivíduos. É nestas condições que prospera o assédio moral, reduzindo, assim, o respeito pelo bem-estar do próximo e o respeito pela dignidade do ser humano.

É baseado nestes factores que o objectivo fundamental desta dissertação consiste em, investigar a relação existente entre a cultura organizacional e a ocorrência ou não do assédio moral no local de trabalho.

Com este estudo esperamos contribuir, para uma compreensão mais científica do assédio moral no trabalho, assim como identificar qual o tipo de cultura organi- 
zacional que pode potenciar o seu aparecimento e/ou a sua prospecção, no sentido de sustentar e orientar a intervenção dos profissionais neste domínio, uma vez que até à data os estudos efectuados têm procurado a prevalência da vitimização por assédio e a sua correlação com variáveis como género, idade, ramo de actividade, número de agressores, entre outras. É pois a aplicação dos conhecimentos em prol da promoção de ambientes organizacionais mais saudáveis o que nos preocupa seriamente, pelo que é nossa intenção a compreensão do fenómeno de tal forma que seja possível, o desenhar de programas de intervenção que tragam ao ambiente de trabalho, climas mais dignos e práticas mais justas em termos da gestão de recursos humanos.

Para apresentar de forma explícita as experiências e a finalidade deste estudo, este artigo encontra-se dividido em dois grandes capítulos, onde são abordadas as duas temáticas, que servem de suporte a esta investigação (assédio moral e cultura organizacional), seguindo-se o método utilizado, a apresentação dos resultados e a sua respectiva análise e discussão, finalizando-se com as conclusões do estudo e sugestões para futuras investigações.

\section{Capítulo 1. Assédio Moral no Trabalho}

$\mathrm{O}$ assédio moral existe desde que surgiram as primeiras relações de trabalho, mas só nos últimos anos tem sido amplamente discutido, principalmente devido às grandes mudanças que surgiram no ambiente de trabalho, com o advento da globalização, que gerou o aumento do desemprego e da concorrência, o que originou a submissão de muitos trabalhadores a situações vexatórias, diante das dificuldades de conseguir "entrar" no mercado de trabalho, cada vez mais exigente, com reduzidas oportunidades de emprego e mais ofertas de profissionais.

Para se entender o conceito de assédio moral, é necessário ter ciente em primeira instância que este fenómeno não ocorre unicamente no local de trabalho, pode estar nos diversos lugares onde são realizadas as mais variadíssimas actividades humanas, como por exemplo, nas escolas, nos transportes públicos, no próprio lar, entre outros. Uma vez percebido que este mal pode ocorrer em qualquer lugar é dedutível que se saiba e, assim pressupõe-se, que o assédio moral é manifestado através de uma conduta de uma pessoa em relação a outra, onde normalmente há entre estas uma relação de subordinação ou dependência, ainda que haja alguma forma de vinculação seja de ordem económica, social ou moral.

Durante toda a existência da humanidade, foram sempre reivindicadas melhores condições de trabalho, com mais segurança, melhor remuneração, entre outras. Neste contexto a luta a favor de um melhor ambiente de trabalho não é recente. Contudo, o problema é que o assédio moral ao longo dos anos foi confundido com outros problemas relacionados com o trabalho, tais como, o stress, as agressões pontuais e conflitos naturais que há entre colegas.

Foi na década de 80 que se iniciaram os estudos acerca do assédio moral, a par- 
tir da divulgação de um ensaio científico de Heinz Leymann, na Suécia, embora já em 1974 Carroll Brodsky, uma psiquiatra americana, definisse o assédio como:

Tentativas, repetidas e persistentes, de uma pessoa a fim de atormentar, frustrar ou quebrar a resistência de outra pessoa, uma tentativa de obter uma reacção do outro. É uma forma de tratamento que, aplicada com persistência, provoca, pressiona, amedronta, intimida e incomoda a vítima. (Brodsky, 1976, p. 7, citado em Soares, 2008, p. 27).

Leymann, introduziu o conceito de bullying para descrever este tipo de agressão no local de trabalho, e desde então inúmeras investigações tiveram lugar para definir com melhor exactidão como é que este fenómeno se manifesta, quais os traços de personalidade e factores organizacionais associados, assim como as suas consequências (Leymann, 1996).

Neste sentido, o conceito de assédio moral no local de trabalho está relacionado com a exposição continuada e persistente a comportamentos negativos e agressivos, de natureza psicológica, descrevendo, portanto, situações em que comportamentos hostis dirigidos sistematicamente a um ou mais colegas, ou subordinados, conduzem à estigmatização e vitimização dos alvos destes comportamentos (Einarsen, 2000).

É um processo tão amplo e complexo que cada área de conhecimento adopta uma definição mais próxima da sua especialidade. No entanto, Marie-France Hirigoyen, descreve uma definição muito pertinente desta forma de "violência moral":

Toda e qualquer conduta abusiva, que se manifesta especialmente por comportamentos, palavras, actos, gestos, escritos, que possam atingir a personalidade, a dignidade ou a integridade física ou psíquica de uma pessoa, pôr em perigo o emprego desta ou degradar o clima de trabalho. (Hirigoyen, 2002, p. 15).

Contudo, independentemente da definição adoptada, é importante reflectir que o que caracteriza este fenómeno é a sistematização e a repetição. Cada agressão isolada não é verdadeiramente grave, mas sim o efeito cumulativo dos pequenos traumatismos sofridos a cada nova agressão (Hirigoyen, 2002). Para a autora um acto isolado, não pode ser considerado como assédio. No entanto, segundo Tehrani (2005), há excepção quando este acto isolado tem reflexo negativo no tempo, ou seja quando o comportamento é tão severo, no caso de violência ou ameaça física, que leva a vítima ao estado de medo permanente. Esta excepção não é ainda consensual entre os pesquisadores desta temática.

Segundo Leclerc (2005), o assédio moral, não é mais do que uma violência institucional que visa à desestabilização psicológica dos trabalhadores e à destruição dos grupos de trabalho, a fim de impor uma lógica organizacional onde os interesses da empresa prevalecem sobre qualquer outra consideração social e humana.

Por outro lado é importante termos ciente que é um fenómeno difícil de provar, no entanto Elisabeth Grebot (2007), considera que compete aos administradores gerir os conflitos para que estes não evoluam para assédio, limitando o uso de técnicas de ataque das relações profissionais, a manipulação de informação e a comunicação pa- 
radoxal, que "envenena" o clima organizacional.

Geralmente o assédio moral envolve não um, mas vários comportamentos negativos. Para Einarsen (2005), os comportamentos negativos, podem classificar-se em dois tipos: assédio relacionado com o trabalho e assédio pessoal. O assédio relacionado com o trabalho implica perseguições direccionadas às actividades e ao desempenho da vítima, tais como metas inatingíveis, sobrecarga de trabalho, ignorar opiniões, excesso de supervisão, reter informações, atribuir tarefas abaixo do nível de competência ou outros tipos de comportamentos que dificultem as condições de realização do trabalho. Já o assédio pessoal refere-se às agressões dirigidas a características ou situações particulares da vítima, como espalhar boatos, criticar persistentemente, gritar, humilhar, isolar e excluir.

\section{Classificação do assédio moral}

Estudos realizados por Leymann (1996), através da aplicação de um questionário em 186 pessoas, apontaram para que em 58\% dos casos o assédio moral vem da administração, em 29\% dos casos vem da chefia, 12\% por parte de colegas e em 1\% dos casos o assédio ocorre por parte de um subordinado.

O assédio moral, quando praticado por um superior hierárquico, é denominado de vertical descendente ou bossing (proveniente do inglês boss - chefe), constituindo o tipo mais frequente.

Quando o assédio moral é o praticado por colegas, denomina-se de assédio horizontal. Neste caso as perseguições são desencadeadas por colegas do mesmo nível hierárquico e são motivados por factores tais como: competitividade por uma promoção, sentimentos de inveja, inimizades por motivos de nível pessoal, entre outros. Este tipo de assédio pode ser praticado individualmente ou em grupo e pode ser desencadeado por um modelo de gestão perversa, em que os colaboradores são tratados como objectos (Guedes, 2003).

Existe um outro tipo de assédio moral, que se denomina assédio misto, que ocorre quando o assédio horizontal se prolonga no tempo e passa a assumir também um assédio vertical descendente, tornando-se o superior hierárquico cúmplice do agressor, por omissão, uma vez que nada fez para resolver a situação da qual tinha conhecimento (Pacheco, 2007).

Por último e menos comum é o vertical ascendente, ou seja de um colaborador para um superior hierárquico. Este tipo de assédio acontece quando um colega é promovido sem que os demais tenham sido consultados, ou ainda, quando há a contratação de uma nova pessoa, cujo estilo e métodos não são aprovados pelos colaboradores, os quais consideram que esta não possui capacidade para desempenhar a função (Pacheco, 2007).

\section{Determinantes do assédio moral}

De entre as explicações que têm vindo a ser sugeridas na literatura europeia para a ocorrência de assédio moral no trabalho, a nível individual, é de destacar a atenção que tem sido dada à personalidade, quer da vítima quer do agressor. Os 
perfis psicológicos da vítima e do agressor podem contribuir para o aparecimento do assédio?

Heinz Leymann (1996), opõe-se fortemente à ideia de que a personalidade da vítima pode ser parte da explicação do fenómeno, argumentando que os factores organizacionais relacionados com a organização do trabalho e com a qualidade dos comportamentos de liderança são as causas fundamentais da ocorrência de assédio moral.

Porém, outros autores entendem que o contributo dos traços de personalidade da vítima não pode ser ignorado num modelo abrangente de assédio moral, quer ao nível do despoletar do processo, quer ao nível da escalada do conflito (Glaso, Matthiesen, Nielsen \& Einarsen, 2007). Este argumento baseia-se na investigação que tem vindo a ser desenvolvida, a qual tem mostrado que quer a vítima quer o agressor evidenciam características de personalidade que podem contribuir para o seu envolvimento em tais situações.

Deste modo, Coyne, Seigne e Randall (2000), afirmam que as vítimas tendem a ser submissas, honestas, conservadoras, sensíveis, responsáveis e ansiosas, são pessoas que preferem evitar o conflito e têm dificuldade em lidar com o stress.

Contudo, Hirigoyen (2002) explica que não há um perfil psicológico que leva uma pessoa a ser vítima de assédio moral e qualquer pessoa poderá ser escolhida. No entanto, comenta que há pessoas que possuem maior propensão para serem assediadas. É o caso, de pessoas atípicas, que se diferenciam do grupo em algum aspecto, por exemplo, sexo, etnia, religião, maneira de falar, de se vestir. Também as pessoas excessivamente competentes, dedicadas, ambiciosas, que podem "causar medo" a um superior ou colega.

Por conseguinte, Guedes (2003) considera que, as vítimas de assédio são indivíduos com imensas qualidades profissionais e pessoais, o que gera no assediador sentimentos de inveja e/ou ciúme. O agressor deposita na vítima todas as suas frustrações e torna-a o "bode expiatório", que paga por um crime da qual é inocente.

Pessoas com um senso de responsabilidade quase patológico, são ingénuas no sentido de que acreditam nos outros e naquilo que eles fazem, são geralmente bemeducadas e possuidoras de valiosas qualidades morais e profissionais. De maneira geral, a vítima é escolhida justamente por ter algo mais. É esse algo mais que o perverso procura tirar (Guedes, 2003, p. 63).

Quanto ao perfil do agressor, que pode ser um único indivíduo ou um grupo. As suas características estão directamente relacionadas com a personalidade, ameaças de perda de poder e liderança negativa. Pretende o controlo e domínio absoluto do assediado, para demonstrar o seu poder e manipulá-lo para obter alguma vantagem, ou pode também ter um intuito de vingança.

Freitas (2001), descreve a perversidade do assediador como algo racional e não patológico.

A perversidade não provém de um problema psiquiátrico, mas de uma racionalidade fria combinada a uma incapacidade de considerar os outros como seres humanos (Freitas, 2001, p. 13).

Para Hirigoyen (2002) os procedimentos hostis do assediador com o assediado são agrupados em quatro categorias, partindo da mais difícil de detectar até à mais evidente: 
i. Atentado às condições de trabalho;

ii. Isolamento e recusa de comunicação;

iii. Atentados contra a dignidade;

iv. Violência verbal, física ou sexual.

Por sua vez, Salin (2003), descreve como características do assediador, a visão negativa dos colaboradores e/ou colegas e a deficiência nas relações sociais. Demonstra dificuldade em assumir responsabilidade no controlo das emoções e revela pouca solidariedade pelos outros.

Apesar do exposto, os estudos revelam que não é possível estabelecer um critério específico de personalidade para vítimas e agressores, Contudo os factores individuais assumem um papel relevante no aparecimento e desenvolvimento do assédio moral.

No que se refere à organização, a necessidade de competitividade, produtividade e eficiência gera uma degradação das condições de trabalho, originando o conflito. Para manter a sobrevivência no mercado, a organização, por vezes, não desenvolve boas políticas de gestão e de organização funcional e direccional. Isto é um factor que, por norma, gera um mau ambiente de trabalho no qual, e nestas condições, é fácil alastrar o assédio moral.

Hirigoyen (1999), relata a existência de "organizações patológicas", estruturalmente perversas, que utilizam a manipulação como forma de aumentar a facturação e atingir objectivos. Nestes ambientes é difícil designar quem é o agressor, descreve-se apenas um ambiente "tóxico". Por conseguinte, nesta perspectiva, pode dizer-se que a organização pode ser, ela própria a assediadora.

No entanto Zapf (1999) contestou a ideia ao afirmar que o assédio moral é um fenómeno que ocorre entre indivíduos e não pode ser atribuído a uma organização, mas por outro lado admite que um conjunto de factores relacionados com a organização pode desencadear este fenómeno. Para o autor, sempre que existem conflitos no seio de uma organização, sem que estes sejam solucionados, há uma maior predisposição para o aparecimento deste fenómeno.

Contudo, as polémicas permanecem, evidenciando múltiplas abordagens. Salin (2003), considera um campo propício para agressões e abuso de poder, originando posteriormente o desencadeamento de assédio, qualquer organização que considere aceitáveis e normais situações de violência, comportamentos anti-sociais e ausência de regras.

Outro aspecto a ser considerado é a influência das culturas locais ou nacionais sobre a forma como o assédio moral é percebido e evidenciado dentro das organizações. Por exemplo, culturas tradicionalmente burocráticas ou com maior distância de poder entre as classes sociais, podem influir na maneira como os conflitos são percepcionados e resolvidos nas organizações. Nalguns países o assédio moral não é muito divulgado e não existe legislação específica, impedindo assim que a vítima se defenda. Por outro lado existem países em que a legislação reforça as medidas preventivas de protecção à vítima deste fenómeno (Einarsen, 2005).

Causas e consequências do assédio moral

São inúmeras as causas do assédio moral nas organizações, especialmente sob a 
liderança autoritária, em que algumas pessoas "explodem" quando deparam com um problema mais grave, ou quando trabalham sobre pressão. Por exemplo, por vezes o empregador serve-se do poder como forma de punição, reprime os colaboradores em ocasiões como reuniões, expondo os seus erros e ignorando que o ser humano é passível de erro. Receber críticas na presença de colegas pode ser devastador para a autoestima. Contudo, quando se tem uma família para sustentar e uma idade avançada o funcionário pode temer enfrentar o problema por medo de ficar desempregado, aceitando assim a humilhação pelo supervisor. Essa situação provoca desmotivação e descontentamento.

Na pesquisa de Vartia (1996) as vítimas acreditavam que as situações de assédio moral eram fruto da falta de informação, do autoritarismo, da falta de objectividade e clarificação quanto aos objectivos da organização e incapacidade de influenciar as decisões. Contudo, Einarsen (2005), notou que as investigações empíricas sobre as causas do assédio moral concentravam-se em dois temas: o papel da personalidade da vítima e o papel de factores psicossociais.

Por outro lado, Leymann (2000) adverte para que o assédio moral provoca efeitos diversos e a vários níveis: organização, indivíduo e sociedade. A sociedade é um dos níveis mais afectados, embora os custos directos e indirectos do assédio moral na sociedade sejam difíceis de contabilizar de forma precisa, pela simples adição dos custos individuais com os custos organizacionais (Di Martino et al., 2003). No entanto, as consequências severas do assédio podem fazer alguma transposição destes custos económicos para a sociedade, devido aos elevados custos que tem de suportar com hospitalizações, medicamentos, baixas por doença e incapacidades (permanentes ou periódicas) para o trabalho. Bem como elevados custos com o desemprego que é originado pelos processos de assédio moral. Segundo o autor os indivíduos tendem a reformar-se mais cedo quando sofrem este tipo de agressão, afectando deste modo todo o sistema social.

Nas organizações temos dois tipos de custos como resultado do assédio moral: os que resultam das consequências que afectam os trabalhadores assediados com custos pelo absentismo e baixas por doenças prolongadas. Num estudo feito por Hirigoyen (1999), 74\% das vítimas faltam ao emprego por consequências de comportamentos de assédio. Por outro lado há custos acrescidos pela necessidade de melhorar o ambiente de trabalho, de combater a falta de motivação pessoal e pela diminuição da produtividade devido à menor eficiência e má imagem da empresa perante os consumidores e mercado de trabalho.

Nos indivíduos, as consequências dependem de pessoa para pessoa, consoante a personalidade, sexo, cultura, entre outros aspectos. Após um longo período de submissão ao assédio moral, muitas vítimas experienciam uma desestabilização permanente. As sequelas deixadas por esta violência perversa podem ir do stress pós-traumático até mesmo a modificações duradouras da personalidade. A vítima permanece com um sentimento de desvalorização, pois como diz um provérbio chinês "Podemos curar-nos de um golpe de espada, mas não de um golpe de língua" (Hirigoyen, 2002, p. 153).

Neste contexto Cristophe Dejours em 2001, realizou três projectos de pesquisa 
numa província do Quebec (Canadá), para medir os níveis de stress em três grupos de trabalhadores consoante a sua exposição ao assédio (tabela 4), sendo o primeiro estudo (E1) composto por trabalhadores do sector do ensino, o segundo (E2) por profissionais de saúde e por último o terceiro (E3) por engenheiros. Concluiu que a presença de sintomas de stress são significativamente mais elevados, quando o indivíduo vivencia o assédio (Soares, 2008).

Tabela 1 - Níveis de stress consoante exposição ao assédio.

\begin{tabular}{lccc}
\hline Variáveis & E1 & E2 & E3 \\
\hline Vítima de assédio no momento da pesquisa (VA) & 38,1 & 35,4 & 35,9 \\
Foi vítima de assédio no ano anterior (FA) & 30,7 & 23,4 & 28,7 \\
Testemunha de assédio (TA) & 25,2 & 19,7 & 17,3 \\
Nunca foi vítima de assédio (NA) & 15,9 & 16,7 & 14,3 \\
\hline
\end{tabular}

Fonte: Adaptado de Soares, A. (2008).

\section{Prevenção e defesa do assédio moral}

Podemos dizer que a prevenção é a primeira e mais efectiva forma de defesa do assédio moral, pois o problema não é do indivíduo, mas sim das condições de trabalho que permitem aos superiores hierárquicos mais espaço para agir.

Segundo Hirigoyen (2002), é importante atribuir responsabilidades à organização na prevenção do assédio moral. Como tal, esta deverá definir estratégias de prevenção e funcionar com regras de ética, uma vez que estas políticas permitem dissuadir os assediadores.

A autora considera, também, importante o envolvimento da sociedade nestas questões. Porque apesar do fenómeno do assédio moral decorrer dentro das organizações tem consequências sociais muito importantes. Como tal, é necessário realizar trabalho no sentido de alterar as mentalidades no que respeita ao tratamento do assédio moral. Por outro lado, conceitua que a vítima também pode desempenhar um papel relevante através da sua postura perante o assédio. Para isso, deverá estar atenta e resistir, manter a sua auto-estima, criar laços de inter-ajuda e solidariedade com os colegas, procurar um interlocutor dentro da organização que possa actuar na situação e procurar apoio jurídico e médico em caso de necessidade.

\section{Capítulo 2. Cultura Organizacional}

\section{Conceito}

Entender o conceito de cultura organizacional implica recuar até aos anos 70 e 80, época em que o estudo da cultura organizacional foi objecto privilegiado de análise científica, bem como um campo de intervenção com atenção crescente por parte de técnicos e consultores em organização e gestão, tornando-se valioso para entender as razões determinantes do desempenho e da qualidade das organizações. 
O conceito e interesse pelo termo "Cultura Organizacional" ficou marcado por Pettigrew (1979), passando a ter um grande desenvolvimento na década de 80, atendendo à tomada de consciência por parte dos investigadores, à importância dos factores culturais nas práticas de gestão e à crença no facto da cultura organizacional constituir um factor que diferencia as organizações bem sucedidas das menos bem sucedidas.

A cultura consiste no modo real de ser e de fazer da organização, isto é, na sua personalidade colectiva, que é constituída, dentre outros aspectos, a partir do modo como as pessoas, em conjunto, pensam e agem, considerando a organização como um todo, assim como o trabalho nela realizado, o seu papel, o seu negócio, os processos de comunicação e relacionamento interpessoal. Deste modo, a cultura organizacional não é mais do que um sistema de significados partilhados, um conjunto de características chave que uma organização valoriza (Robbins, 1999).

Todavia, o termo "cultura" começou por ser definido como um componente do sistema social, o qual se manifesta pelo modo de vida e pelos artefactos, onde se incluem o saber, a crença, a arte, a moral, a lei, os costumes e hábitos assumidos pelo homem como membro da sociedade (Neves, 2000).

Segundo Smircich (1983) a cultura organizacional representa o sistema de comportamentos, normas e valores sociais, aceites e partilhados por todos os membros da organização e que de certa forma a tornam única. Transmite a forma como os membros da organização se comportam de acordo com o sistema de valores vigente.

Para o autor, a importância da cultura organizacional deve-se ao facto de constituir uma forte determinante da motivação na organização, facto esse, que se deve às funções que desempenha.

As organizações são também compostas por estruturas humanas e sociais, com vida própria, que crescem, desenvolvem-se e adaptam-se às exigências da envolvente em que se inserem, interna e externa, mediata em termos de perspectiva económica, tecnológica, cultural, política e demográfica, e imediata nas áreas de análise do cliente, mercado, concorrentes ou sectores de actividade (António, 2003).

Para Edgar Schein (2004) a cultura é uma abstracção, ainda que as forças criadas em situações sociais e organizacionais que dela derivam sejam poderosas. $\mathrm{O}$ autor sublinha que um dos aspectos mais enigmáticos, quando se perspectiva o conceito de cultura, é que aponta para um fenómeno que está sob a superfície, poderoso no seu impacto, mas invisível e até certo ponto, inconsciente. Neste sentido, como afirma Bilhim (2009, p.83), "A cultura está para a organização, assim como a personalidade está para o indivíduo".

Actualmente as recentes pesquisas das organizações consideram a Cultura Organizacional imprescindível no funcionamento das empresas e na determinação da sua eficácia (Yilmaz \& Ergun, 2008, citados por Santos e Gonçalves, 2010).

Dimensões da cultura organizacional

De acordo com De Witte e De Cock (1986), a cultura organizacional tem origem em duas dimensões unipolares (controle e dinamismo) que têm uma variação en- 
tre "muito e pouco" e que se encontram relacionadas entre si. Em torno destas duas dimensões organizacionais, estruturam-se quatro quadrantes, constituindo as culturas de regras, apoio, inovação e de objectivos. A cultura de regras caracteriza-se por pouco dinamismo e muito controle, a cultura de apoio por pouco dinamismo e pouco controle, a cultura de inovação por muito dinamismo e pouco controle e por fim, a cultura de objectivos caracteriza-se por muito dinamismo e muito controlo.

Abordagem ao modelo dos valores contrastantes

Este modelo foi proposto por Quinn e McGrath em 1985 para a cultura organizacional e procura ser uma forma inovadora de abordar o problema da evolução dinâmica da cultura.

Segundo Quinn (1996), não existe uma única cultura, cada organização enquadra-se em vários vectores culturais, ou seja, pode num primeiro momento enfatizar uma determinada cultura e posteriormente privilegiar outro enquadramento cultural, ou num mesmo momento, face a situações diferentes, utilizar simultaneamente culturas distintas.

Na figura 1, encontram-se representados os quatro modelos culturais nos quais, segundo o autor, a organização pode actuar de acordo com os seus interesses. Este modelo assenta na análise a partir de três eixos: i) Eixo Vertical - com incidência na flexibilidade ou no controlo, predomina uma orientação para a estabilidade ou para a mudança; ii) Eixo Horizontal - valoriza o nível individual (micro) ou o organizacional (macro), há uma orientação para o desenvolvimento das pessoas ou para a competitividade da organização; iii) Eixo Diagonal - há uma tendência direccional para os meios (planeamento) ou para os fins (produtividade), a orientação consiste nos processos ou nos resultados.

Da combinação destes três eixos resultam quatro quadrantes, que representam quatro orientações de gestão, conforme identificado na figura 1:

i. A Cultura de Apoio - que enfatiza a flexibilidade e o lado interno da organização e tem como principal objectivo a criação e manutenção da coesão e empenho das pessoas.

ii. A Cultura de Inovação - valoriza a flexibilidade e a mudança, mas centra a atenção na adaptação da organização às exigências da envolvente externa. $\mathrm{Na}$ base da motivação estão o desafio e iniciativa individual. A eficácia vai ser medida pela quota de mercado e pelo crescimento em volume de negócios.

iii. A Cultura Racional (de objectivos) - dá importância à produtividade, ao desempenho, ao alcance dos objectivos e à realização, consistindo a motivação na capacidade de competir e de alcançar os objectivos predeterminados.

iv. A Cultura Burocrática (de regras) - valoriza a formalização e segurança, a uniformidade e a centralização, em nome de uma estabilidade interna. O que vai constituir o factor de motivação é a segurança, a ordem, as regras e as normas de funcionamento organizacional. 
Figura 1 - Modelo de cultura organizacional

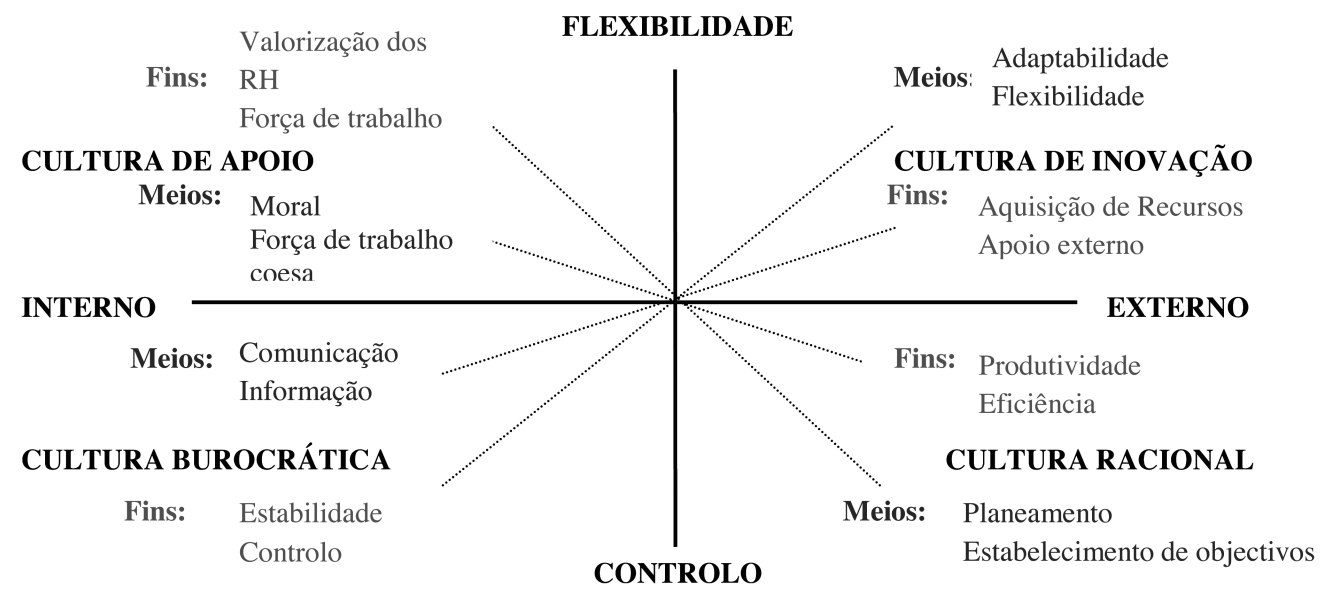

Fonte: Adaptado de Quinn \& McGrath (1985).

Segundo o modelo dos valores contrastantes, cada tipo de cultura tem o seu oposto com que contrasta e os seus paralelos com que partilha características. Por isso, a cultura de apoio que enfatiza a flexibilidade e a orientação interna, contrasta com a cultura racional, cuja importância é o controlo e a orientação externa; apresenta semelhanças com a cultura de inovação, na medida em que ambas partilham a ênfase na flexibilidade e, semelhanças também com a cultura burocrática, na medida em que as duas partilham a ênfase no interno. O oposto da cultura de inovação é a cultura burocrática. Enquanto a primeira dá importância à flexibilidade e ao externo, a segunda valoriza o controlo e o interno. A cultura de inovação partilha características (flexibilidade) com a cultura de apoio e com a cultura racional.

De acordo com este modelo, os valores, as crenças, as atitudes e os pressupostos fundamentais, cujo significado é partilhado pelos membros de uma organização constituem a essência da cultura organizacional. Tal partilha traduz uma visão comum acerca de diversos aspectos da natureza e do funcionamento organizacional, tais como: relacionamento interpessoal, objectivos, regras e normas da organização, comportamentos apropriados, modos de resolver problemas.

\section{Método}

O método adoptado no presente estudo foi o quantitativo através da passagem dos questionários que configuram os instrumentos de recolha de dados sobre a cultura organizacional o FOCUS 93 (First Organizational Climate and Culture Unified Survey) de Witte e VanMuijen (1994) e sobre a percepção dos respondentes acerca da existência de assédio moral o NAQ - R (Negative Acts Questionnaire Revised) (de Einarsen e Hoel (2001). Integrado no processo de recolha de dados foi passada uma ficha demográfica. 


\section{Objectivos e Hipóteses}

Os objectivos e hipóteses decorrem da revisão da literatura, já apresentada. Conforme referido anteriormente, um problema sério em termos sociais, profissionais e humanos ao qual é necessário dar resposta, é a violência no local de trabalho, em particular, o assédio moral. Neste sentido, é fundamental avaliar a relação existente entre a cultura organizacional e o aparecimento deste fenómeno, o que constitui o objectivo geral deste trabalho. O estudo que agora se apresenta pretende atingir os seguintes objectivos específicos:

i. Avaliar a percepção dos colaboradores acerca da existência do assédio moral; fenómeno

ii. Analisar o tipo de cultura organizacional que potencia o aparecimento deste

De acordo com os objectivos enunciados anteriormente, e em sintonia com a revisão da literatura, formulamos as hipóteses que se seguem:

Hipótese 1: $\mathrm{O}$ assédio moral pode ser percepcionado pelos funcionários.

Hipótese 2: A cultura organizacional pode ser potenciadora do assédio moral no local de trabalho.

Hipótese 3: $\mathrm{O}$ assédio moral pode ser causa de absentismo nas organizações.

\section{Participantes}

Participaram desta investigação 150 (cento e cinquenta) sujeitos trabalhadores na área da saúde, em contexto privado, mais concretamente dentro da Medicina Dentária e 150 (cento e cinquenta) sujeitos do sector bancário, nas agências da Caixa Geral de Depósitos (CGD), uma vez que foram as agências onde nos colocaram menos entraves para a elaboração da nossa pesquisa.

Após obtermos autorização de todas as organizações, foi determinada uma amostra probabilística (Pestana \& Velosa, 2002) através da selecção aleatória estratificada proporcional da população em cada organização, com o auxílio dos recursos humanos, que nos facultaram uma base de dados com as funções existentes, para procedermos de igual modo ao nivelamento em termos de categoria profissional, onde optámos por um nivelamento clássico de seis níveis: Direcção Geral, Direcção Intermédia, Técnico Superior, Técnico Profissional, Administrativos e Pessoal Auxiliar, conforme Tabela 2.

Tabela 2 - Nível hierárquico da amostra.

\begin{tabular}{lcccccc}
\hline Categoria Profissional & \multicolumn{2}{c}{ CDG } & \multicolumn{2}{c}{ Dentária } & \multicolumn{2}{c}{ Total } \\
& n & $\%$ & $\mathbf{n}$ & $\%$ & $\mathbf{n}$ & $\%$ \\
\hline Pessoal auxiliar & 25 & 8,3 & 87 & 29,0 & 112 & 37,3 \\
Administrativo & 50 & 16,7 & 14 & 4,6 & 64 & 21,3 \\
Técnico Profissional & 35 & 11,7 & 11 & 3,7 & 46 & 15,4 \\
Técnico Superior & 16 & 5,3 & 32 & 10,7 & 48 & 16,0 \\
Direcção Intermédia & 14 & 4,7 & 4 & 1,3 & 18 & 6,0 \\
Direcção Geral & 10 & 3,3 & 2 & 0,5 & 12 & 4,0 \\
\hline
\end{tabular}




\section{Instrumentos}

Utilizámos o Focus-93 (First Organizational Climate and Culture Unified Survey) utilizado por De Witte e Van Muijen em 1994, uma vez que já se encontra validade para a população portuguesa; o questionário NAQ-R - Negative Acts Questionnaire Revised (Einarsen \& Hoel, 2001) em versão validada por análise factorial, que consiste numa versão constituída por dezanove itens com cinco opções de resposta, estruturadas numa escala Likert, cada uma correspondendo a um determinado grau de ocorrência dos comportamentos expressos no conteúdo dos itens, em relação ao respondente. De seguida foi apresentada uma definição de assédio moral utilizada por Ana Verdasca (2010), depois de devidamente autorizado por correio electrónico, de forma a avaliar a percepção de ser alvo de assédio moral:

$\mathrm{O}$ assédio moral no trabalho consiste em comportamentos negativos e agressivos, com uma dimensão política, de carácter persistente e duradouro no tempo, incluindo assediar, humilhar, ofender ou excluir socialmente um ou mais indivíduos, afectando negativamente o seu desempenho profissional e/ou criando um ambiente de trabalho hostil. O assédio é um conflito em escalada, envolvendo um desequilíbrio de poder, no decorrer do qual o alvo dos comportamentos agressivos e hostis tem dificuldades em se defender com sucesso. (Verdasca, 2010, p. 256).

Foi depois solicitada a resposta a diversas questões relacionadas com este fenómeno, tais como: género do agressor, duração da agressão, número de agressores, entre outras.

\section{Procedimentos}

Para se obter a informação necessária para este estudo, foi previamente marcado por via telefónica, um dia e local com os Administradores/Gerentes de cada organização. Posteriormente no dia combinado, deslocámo-nos às instalações das referidas organizações, onde se procedeu a uma breve explicação acerca do tema em questão e acerca do seu objectivo, clarificando a confidencialidade da informação. Seguiu-se a obtenção da autorização com consentimento informado por escrito. Posteriormente procedeu-se à marcação do dia e local para preenchimento dos questionários, pelos respectivos colaboradores de cada empresa.

Antes da distribuição dos questionários, efetuou-se uma breve explicação acerca do objectivo do estudo, entregando a cada um dos respondentes uma carta de apresentação do mesmo, clarificando uma vez mais a confidencialidade da informação, promovendo assim uma maior sinceridade nas respostas. O consentimento informado foi feito verbalmente a todos em simultâneo, seguindo-se a entrega dos questionários e esclarecimentos de dúvidas individuais, quando solicitadas. $\mathrm{O}$ tempo de duração foi flexível às necessidades dos participantes.

Os resultados foram alvo de procedimentos estatísticos com utilização do PASW Statistics (Predictive Analytics Software), ex-SPSS (Statistical Package for the Social Sciences), versão18 para Windows. 


\section{Resultados}

Os resultados que se apresentam de seguida, organizam-se com o intuito de responder às questões de investigação que orientaram este estudo.

Recorreu-se a estatísticas paramétricas quando a normalidade da distribuição e homogeneidade de variância eram respeitados, recorrendo-se a estatísticas não paramétricas quando estes parâmetros não eram respeitados. Apresentaram distribuição normal ou próximo da normalidade os valores nas escalas do FOCUS-93. Apresentaram distribuição não paramétrica os valores nas escalas do NAQ-R. Estes dados foram tidos em consideração na escolha dos procedimentos estatísticos.

O primeiro objectivo deste estudo consiste na avaliação da percepção dos colaboradores acerca da existência do assédio moral no local de trabalho. Dos 300 participantes deste estudo, $60,6 \%(n=182)$, referem ter sido vítimas de assédio moral no trabalho, 27,7\% $(n=83)$, referem ter sido raramente assediadas e $11,7 \%(n=35)$, nunca sofreram assédio moral nos últimos 12 meses (tabela 3).

Tabela 3 - Distribuição das respostas por terem sido alvo de assédio moral no local de trabalho nos últimos 12 meses.

\begin{tabular}{lcc}
\hline & Frequência & Percentagem \\
& $\mathbf{n}$ & $\mathbf{0}$ \\
\hline Sim, pelo menos uma vez por dia & 34 & 11,3 \\
Sim, pelo menos uma vez por semana & 42 & 14,0 \\
Sim, pelo menos uma vez por mês & 106 & 35,3 \\
Raramente & 83 & 27,7 \\
Nunca & 35 & 11,7 \\
\hline Total & 300 & 100,0 \\
\hline
\end{tabular}

No entanto para que não restassem dúvidas, efectuámos um teste de hipótese para verificar a percepção do assédio moral dos inquiridos da nossa amostra. Para isso acrescentámos uma nova variável à nossa base de dados, que consistiu na média de todos os comportamentos negativos apontados pelos inquiridos do nosso estudo na tentativa de responder à primeira hipótese do nosso estudo, que consiste em "avaliar a percepção do assédio pelos funcionários", temos como hipótese nula (H0): O Assédio Moral é percepcionado pelos funcionários e como hipótese alternativa (H1): O Assédio Moral não é percepcionado pelos funcionários, ou seja, $\mathrm{H} 0$ : $\mu \leq 3$ versus $\mathrm{H} 1: \mu>3$.

Tabela 4 - Percepção do assédio moral.

\begin{tabular}{cccc}
\hline Variável Dependente & Mediana & Desvio Padrão & Teste Estatístico \\
& $\boldsymbol{\mu}$ & ठ & \\
\hline Assédio Moral & 3 & 0,589 & $\mathrm{U}=2,317$; $\mathrm{p}$-value $=0,134$ \\
\hline
\end{tabular}


Conforme podemos verificar na tabela 4 , obtemos para um nível de significância de $5 \%$, um p-value $>0,05$, pelo que a nossa hipótese nula não deve ser rejeitada, logo implica afirmar que os funcionários percepcionam quando são alvos de assédio moral.

Para atingir o segundo objectivo deste estudo, que consiste na análise do tipo de cultura que pode ser potenciadora deste fenómeno, procedemos em primeiro lugar à análise do tipo de cultura que segundo a percepção dos inquiridos do nosso estudo predomina nas respectivas empresas. Para isso, procedeu-se à introdução de quatro novas variáveis, que consistiu no cálculo das médias de todas as variáveis constituintes de cada dimensão (Apoio, Inovação, Regras e Objectivos), relativamente ao seu conteúdo (Modelos dos Valores Contrastantes de Quinn \& McGrath, 1985), e efectuámos a comparação entre os resultados obtidos. Estes apontam para uma predominância do factor "objectivos", tanto no clima como na cultura organizacional. Conforme consta na tabela 5, a média desta frequência não se distancia muito do factor "regras"e por outro lado a diferença entre este e o factor "apoio" já é bastante significativa.

Tabela 5 - Comparação das tendências dos resultados da aplicação do questionário Focus -93 .

\begin{tabular}{lcccc}
\hline \multirow{2}{*}{ Factores } & \multicolumn{2}{c}{ Clima } & \multicolumn{2}{c}{ Cultura } \\
\cline { 2 - 5 } & Média & Desvio Padrão & Média & Desvio Padrão \\
\hline Apoio & 2,78 & 0,47 & 2,30 & 0,57 \\
Inovação & 3,13 & 0,51 & 3,21 & 0,50 \\
Regras & 3,30 & 0,48 & 3,71 & 0,62 \\
Objectivos & 3,33 & 0,56 & 3,85 & 0,46 \\
\hline
\end{tabular}

Conforme os resultados mostrados na tabela 5, as respostas dos inquiridos do presente estudo, descrevem-nos a cultura das empresas onde trabalham, como uma cultura de objectivos $(\mu=3,85)$, sendo de igual forma o factor objectivos o mais predominante em relação ao clima organizacional $(\mu=3,33)$, por outro lado, os que obtiveram as médias inferiores foram respectivamente o factor apoio no clima $(\mu=2,78)$ e a cultura de apoio $(\mu=2,30)$. Podemos concluir destes dados que segundo a teoria do Modelo dos Valores Contrastante de Quinn, nestas empresas dá-se importância à produtividade, ao desempenho, a alcançar os objectivos e à realização. A motivação consiste na capacidade de competir e de alcançar os objectivos pré-determinados.

Pela análise destes resultados podemos concluir que os mesmos se encontram em consonância com a teoria de Ashkanasy, Wilderon e Peterson (2000), quando afirmam que clima e cultura formam um "common-lay", ou seja não são completamente distintos, o que confirmamos com o nosso estudo, uma vez que os resultados apontam para tendências semelhantes em termos de clima e cultura organizacional.

Neste sentido e de acordo com a teoria de Quinn (1996), não prevalece numa determinada empresa uma só cultura, mas sim um conjunto de regras que podem estar mais direccionadas para o "foco" interno ou "foco" externo, consoante aquilo que se pretende atingir. 
Numa análise geral dos dados podemos verificar que estas empresas colocam uma grande ênfase no controlo e foco externo e dão importância aos critérios de eficácia, de planear e alcançar metas (como meios) e produtividade e eficiência (como fins), confirmando assim o que nos revela o Modelo dos Valores Contrastantes que serviu de base a esta pesquisa. A cultura organizacional das empresas pesquisadas está claramente orientada para a competitividade externa, para a aquisição de recursos e para a maximização dos resultados, sendo classificada como Cultura Racional (Objectivos).

De seguida, como o nosso objectivo principal é verificar se a cultura organizacional é potenciadora de assédio moral no local de trabalho, procedemos num primeiro plano ao estudo da relação existente entre assédio moral e cultura organizacional, através do Teste de Correlação de Spearman.

Tabela 6 - Relação entre cultura organizacional e assédio moral.

\begin{tabular}{lllll}
\hline \multirow{2}{*}{ Spearman's rho } & \multicolumn{2}{c}{ Assédio Moral } & \multicolumn{2}{c}{ Cultura Organizacional } \\
\cline { 2 - 5 } & $\mathbf{r}$ & $\mathbf{p}$-value & $\mathbf{r}$ & p-value \\
\hline Assédio Moral & 1 & & 0,546 & 0,134 \\
Cultura Organizacional & 0,546 & 0,134 & 1 & \\
\hline
\end{tabular}

Nível de significância a $1 \%$

Podemos verificar através dos resultados da tabela 6 , que a cultura organizacional correlaciona-se positivamente com o assédio moral $(\mathrm{r}=0,546)$ e que podemos considerar esta relação forte $(r>0,50)$.

Para testar a nossa Hipótese 2 "A Cultura Organizacional pode ser potenciadora de Assédio Moral no Local de Trabalho", utilizou-se a análise de regressão linear, em que a variável assédio moral entrou como variável dependente e as subescalas da cultura organizacional (apoio, inovação, regras e objectivos), como variáveis independentes. Os resultados da tabela 7, apontam para a existência de uma forte relação entre a cultura de objectivos e o assédio moral $(\mathrm{r}=0,978)$, existindo também uma forte relação com a cultura de regras, uma vez que quando uma aumenta a outra tende também a aumentar. A cultura de inovação tem uma relação moderada e ao contrário de todas as outras, a cultura de apoio tem uma relação fraca com o assédio moral $(\mathrm{r}=0,266)$.

Mediante os resultados observados, não rejeitamos a nossa hipótese nula, podendo assim afirmar, que a cultura organizacional nas empresas pesquisadas é potenciadora de assédio moral no local de trabalho, nomeadamente pelos valores reflectidos na cultura de objectivos e regras.

Obviamente que os resultados têm explicação significativa para os casos em que o factor cultural predominante seja o de objectivos e/ou de regras. 
Tabela 7 - Análise de regressão múltipla entre assédio moral e as subescalas da cultura organizacional.

\begin{tabular}{lccccc}
\hline & \multicolumn{5}{c}{ Assédio Moral } \\
\cline { 2 - 6 } & $\mathbf{R}$ & $\mathbf{R 2}$ & $\boldsymbol{\beta}$ & $\mathbf{t}$ & p-value \\
\hline Cultura de Apoio & 0,236 & 0,189 & 0,220 & 4,126 & 0,000 \\
Cultura de Inovação & 0,389 & 0,261 & 0,283 & 4,936 & 0,000 \\
Cultura de Regras & 0,582 & 0,506 & 0,113 & 1,452 & 0,148 \\
Cultura de Objectivos & 0,978 & 0,903 & 0,029 & 0,354 & 0,723 \\
\hline
\end{tabular}

Nível de significância a 5\%, R (coeficiente de correlação), $\mathrm{R}^{2}$ (coeficiente de determinação), $\mathrm{t}$ (valor observado).

Por último, para testar a Hipótese 3 "O assédio moral pode ser causa de absentismo nas organizações" em primeiro lugar analisámos a correlação existente entre ambos e posteriormente efectuámos uma análise de regressão, concluindo que o assédio moral não é causa de absentismo no "seio" da nossa amostra, conforme dados da tabela 8 e 9 respectivamente.

Verificamos um p-value $<0,50$ (inferior ao nível de significância), logo rejeitamos a nossa hipótese nula, que previa o assédio moral como causa de absentismo.

Em contradição com estudos anteriores e com a pesquisa bibliográfica que efectuámos, os inquiridos do nosso estudo, não faltam ao trabalho por motivos de assédio moral, tal facto deve-se provavelmente por terem desenvolvido estratégias de evitamento de forma a superar o stress causado por este fenómeno. Por outro lado, como a taxa de vítimas de assédio deste estudo é elevada, pode acontecer que haja, ao contrário de estudos anteriores, solidariedade e compaixão da parte de alguns colegas de trabalho. Em determinados relatos, algumas vítimas afirmam que: "[...] não sei o que será pior - se o assédio, se a traição.” (Matias, 2010)

Tabela 8 - Relação entre assédio moral e absentismo.

\begin{tabular}{lcccc}
\hline & \multicolumn{2}{c}{ Assédio Moral } & \multicolumn{2}{c}{ Absentismo } \\
\cline { 2 - 5 } & $\mathbf{r}$ & p-value & r & p-value \\
\hline Assédio Moral & 1 & & 0,128 & 0,027 \\
Absentismo & 0,128 & 0,027 & 1 & \\
\hline
\end{tabular}

Nível de significância a 5\% 
Tabela 9 - Análise de regressão linear entre assédio moral e absentismo.

\begin{tabular}{lrrrrr}
\hline & \multicolumn{5}{c}{ Assédio Moral } \\
\cline { 2 - 6 } & $\mathbf{R}$ & $\mathbf{R 2}$ & $\boldsymbol{\beta}$ & $\mathbf{t}$ & p-value \\
\hline Absentismo & 0,128 & 0,016 & 0,128 & 2,220 & 0,027 \\
\hline
\end{tabular}

Nível de significância a 5\%

\section{Discussão}

Os resultados obtidos, com utilização dos mesmos modelos, registaram um significativo grau de fiabilidade para uma reflexão aturada em face de outros estudos realizados. O modelo dos valores contrastantes e o questionário Focus-93 já anteriormente testado mostrou-se adequado na avaliação da cultura organizacional. Da mesma forma o modelo de Hirigoyen e o questionário NAQ-R, validado por Ana Verdasca na sua tese de doutoramento, demonstrou ser uma mais-valia na pesquisa e avaliação do assédio moral no trabalho.

Estes dados não podem ser reportados para a população em geral, uma vez que se trata de uma amostra relativamente reduzida $(n=300)$ e por ter sido efectuada apenas na região centro do País.

Ao analisarmos os resultados, verificámos que, o assédio moral é percepcionado pelos trabalhadores. Por outro lado, constatamos que a cultura organizacional é potenciadora do assédio moral, o que vai de encontro à teoria de Leymann (1996), que considera que os factores organizacionais relacionados com a organização do trabalho e com a qualidade dos comportamentos de liderança, são as causas fundamentais da ocorrência de assédio moral. Os resultados do nosso estudo relevam que o assédio moral não se apresenta como sendo causa de elevado e continuado absentismo nas organizações o que pode dever-se, entre outros fatores, ao medo do despedimento.

Nas empresas estudadas há uma predominância da cultura de objectivos, que consiste na valorização da estabilidade e controlo, com uma orientação para a competitividade da organização.

\section{Conclusão}

Este estudo teve como principal enfoque a avaliação do nível de percepção dos respondentes sobre a existência de assédio moral nas organizações onde laboram e observar a relação condicionante com a cultura organizacional

Em face dos resultados obtidos podemos considerar, no contexto desta investigação que existe correlação entre a cultura organizacional e o assédio moral nomeadamente no que refere à cultura por objectivos, em que o assédio se afigura mais emergente, onde factualmente o enfoque não se encontra na pessoa mas na mensurabilidade do produto final. Relativamente às hipóteses formuladas, os resultados obtidos confir- 
mam que existe percepção por parte dos colaboradores acerca deste fenómeno e o facto da cultura organizacional ser potenciadora do mesmo.

Este estudo foi importante, por poder contribuir na pesquisa de questões relacionadas com o assédio moral que se observa como uma situação silenciosa em termos de denúncia mas muito doloroso no que concerne às vítimas. Igualmente foi importante perceber a importância da organização mental das organizações no que respeita à forma como são percepcionados e geridos os recursos humanos.

Os resultados da pesquisa em função dos níveis de prevalência de assédio moral sugerem que as organizações estão a ser geridas duma forma inadequada no que se refere aos aspectos relacionados com o factor humano e organização de tarefas. A lógica mecanicista da função e a atribuição significativa do "homum numerus" configura uma estrutura funcional que não observa os factores de motivação e auto-estima como elementos fulcrais para o desempenho e qualidade de vida. Torna-se imprescindível uma mudança, que contemple o todo das organizações e que possa ser empreendida de forma segura e eficaz. A pressão psicológica subjacente ao assédio moral catalisa estímulos stressores de efeito negativo com consequências que podem ser graves para o trabalhador e para a organização.

Apesar da amostra deste estudo ter sido muito reduzida, e não se generalizar para a população em geral, afigura-se-nos que pode ter fornecido contributos para a reflexão sobre as práticas organizacionais, de modo a sensibilizar e consciencializar que o reconhecimento e a prevenção do fenómeno pode proporcionar uma melhor qualidade de vida aos seus colaboradores aumentando o seu nível de resiliência e dotar as organizações de um insight colectivo que possa ser potenciador de encontrar caminhos alternativos nas adversidades do quotidiano.

Ainda no contexto dos resultados apresentados fica a noção de ser uma pesquisa inacabada emergindo a necessidade de novas pesquisas a fim de melhor compreender o assédio moral no local de trabalho, associando-o a outros componentes do comportamento organizacional e/ou individual quer da parte do assediador quer do assediado.

Afigura-se-nos como pertinente a necessidade de informar e consciencializar os trabalhadores em todos os seus aspectos, inclusive as formas como o assédio se exterioriza, as responsabilidades envolvidas e os riscos que dele derivam para a saúde, sem esquecer a importância da postura solidária dos colegas, em relação ao assediado, conforme resultado do nosso estudo.

Como psicólogos sociais e organizacionais, consideramos de extrema necessidade preservar a saúde psicológica dos trabalhadores, que é um dos valores inerentes à própria dignidade humana. Neste sentido, a promoção da prevenção e defesa do assédio moral através da informação, prevenção e intervenção multidisciplinar é de crucial importância.

A finalização deste estudo permitiu compreender que a percepção do fenómeno do assédio é real mas que continua envolvida pelo medo de represálias em face de uma inexistente plataforma de intervenção e nesse sentido esperamos ter contribuído um pouco mais para dar foco no estudo do fenómeno de forma continuada e mais global 
Não nos devemos esquecer que a qualquer momento podemos ser "a próxima vítima” É importante lembrar que, o medo reforça o poder do agressor!

\section{Referências}

António, N. S. (2003). Estratégia Organizacional: do posicionamento ao Movimento. Lisboa: Edições Sílabo.

Bilhim, J. A. F. (2009). Gestão Estratégica de Recursos Humanos. (4a ed.). Lisboa: Instituto Superior de Ciências Sociais e Políticas.

Coyne, I.; Seigne, E. \& Randall, P. (2000). Predicting Workplace Victim Status From Personality. European Journal of Work and Organizational Psychology, 9 (3), 335-349.

De Witte, K. \& De Cock, G. (1986). Organizational Climate: It's Relationship with Managerial Activities and Communication Structures. In G. Debus \& H.W. Schroiff (Eds.). The Psychology of Work Organization. North Holland: Elsevier Science.

Dejours, C. (1998). La Souffrance en france. La banalisationa de l'injustice social. Paris: Seuil.

Di Martino, V. ; Hoel, H. \& Cooper, C. (2003). Preventing violence and harassment in the workplace. European foundation for the improvement of living and working conditions. Ireland.

Einarsen, S. (2000). Harassment and bullying at work: A review of the Scandinavian approach. Aggression and Violent Behaviour, 5(4), 379-401.

Einarsen, S. (2005). The nature, causes and consequences of bullying at work: the Norwegian experience. In S. Einarsen; H. Hoel; D. Zapf \& C. L. Cooper (eds). Bullying and harassment in the workplace: Development in theory, research and practice (2nd ed.). London: Taylor \& Francis.

Einarsen, S. \& Hoel, H. (2001, Maio). The Negative Acts Questionnaire: Development, validation and revision of a measure of bullying at work. Paper presented at the 10th European Congress at work and Organizational Psychology, Prague.

Freitas, M. E. (2001). Assédio moral e assédio sexual: faces do poder perverso nas organizações. RAE - Revista de Administração de Empresas, 41 (2). São Paulo: Fundação Getulio Vargas.

Glaso, L.; Matthiesen, S. B.; Nielsen, M. B. \& Einarsen, S. (2007, Abril). Do targets of workplace bullying portray a general victim profile, Scandinavian Journal of Psychology, 48, 313-319.

Grebot, E. (2007). Harcélement au travail: identifier, prevenir, désarmorcer. Paris: Eyrolles Éditions d'Organisation. 
Guedes, M. N.(2003). Terror Psicológico no Trabalho. São Paulo: LTr.

Hirigoyen, M. F. (1999). Assédio, Coacção e Violência no Quotidiano. Lisboa: Pergaminho.

Hirigoyen, M. F. (2002). Assédio no Trabalho: como distinguir a Verdade. Lisboa: Pergaminho.

Leclerc, C. (2005). Intervenir contre le harcèlement au travail : Soigner et sévir ne suffisent pas. Numéro spécial sur le harcèlement psychologique au travail. Pistes, 7(3). Disponível em http://www.pistes.uqam.ca/v7n3/articles/v7n3a4.htm, acesso em 01 de Abril de 2011.

Leymann, H. (1996). Mobbing: La persécution au travail. Paris: Editions du Seuil.

Leymann, H. (2000). Bullying; Whistleblowing: Consequences of mobbing in The Mobbing Encyclopedia. Disponível em http://www.leymann.se/English/frame.html, acesso em 24 de Maio de 2010.

Matias, M. (2010, Novembro, 18). Histórias de terror no trabalho. Revista Visão, 924, 118-132.

Neves, J. G. (2000). Clima Organizacional, Cultura Organizacional e Gestão de Recursos Humanos. Lisboa: Editora RH.

Pacheco, M. G. R. (2007). O Assédio Moral no Trabalho: O Elo Mais Fraco. Coimbra: Edições Almedina.

Pestana, D. \& Velosa, S. (2002). Introdução à Probabilidade e à Estatística (Vol.1). Lisboa: Fundação Calouste Gulbenkian.

Pettigrew, A. M. (1979). On studying organizational cultures. Administrative Science Quartely, 24, 570-581.

Quinn, R. E. (1996). Deep Change: Discovering the Leader Within. San Francisco: Jossey-Bass.

Quinn, R. E. \& McGrath, F. R. (1985). The Transformation of Organizational Cultures: A Competing values Perspective. In P. J. Frost; L. F. Moore; M. R. Louis; C. C. Lundberg \& J. Martin (Eds.). Reframing Organizational Culture. London: Sage Publications.

Robbins, S. P. (2004). Fundamentos do Comportamento Organizacional. São Paulo: Prentice Hall.

Salin, D. (2003). Ways of explaining workplace bullying: A review of enabling, motivating and precipitating structures and processes in the work environment. $\mathrm{Hu}$ mans Relations, 56 (10), 1213-1232.

Santos, J. V. \& Gonçalves, G. (2010). A Cultura Organizacional: O impacto visível de uma dimensão invisível. Psicologia, 41 (3), 393-398.

Schein, E. (2004). Organizational Culture and Leadership (3rd. Revised Edition). San Francisco: Jossey-Bass Publishers. 
Smircich, L. (1983). Concept of Culture and Organizational Analysis. Administrative Science Quartetly, 3, 339-358.

Soares, A. (2008, Maio/Junho). Assédio moral: o stresse das vítimas e das testemunhas. Revista Segurança, 184, 27-29. Lisboa: Inovergo.

Tehrani, N. (2005). Bullying at Work: Beyond Policies to a Culture of Respect. London: CIPD. Disponível em http://cipd.co.uk/hr-resourses/guides/bullying-workbeyond-policies-culture-respect.aspx, acesso em 12 de Dezembro de 2010.

Vartia, M. (1996). The sources of bullying - psychological work environment and organizational climate. European Journal of Work and Organizational Psychology, 5 (2), 203-214.

Verdasca, A. T. M. (2010). Assédio Moral no Trabalho - Uma aplicação ao sector bancário português. Tese de doutoramento em Sociologia Económicas e das Organizações, disponível online no repositório do ISEG, disponível em http://www.repository.utl.pt, acesso em 22 de Janeiro de 2011.

Zapf, D. (1999). Mobbing in Organisatinen. Ein Uberlick zum Stanbd der Forschung, Zeitschrift fur Arbeits ad Organizationspsychologie, 43, 1-25. 